\title{
JACOB HEPKEMA EN DE INTRODUCTIE VAN DE MODERNE JOURNALISTIEK IN FRIESLAND
}

Toen Jacob Tjebbes Hepkema op I3 juli I9ı9 overleed, was dat nieuws in Friesland. Hij was een bekende persoonlijkheid, in de eerste plaats vanwege zijn kranten. Het Nieuwsblad van Friesland en het Leeuwarder Nieuwsblad werden in de volksmond zelfs 'de Hepkema' genoemd. Zijn begrafenis trok grote publieke belangstelling en er werden uitgebreide verslagen van geplaatst in Hepkema's eigen bladen. Zelfs zijn eeuwige concurrent, de Leeuwarder Courant, besteedde er aandacht aan en erkende dat hij zijn blad tot grote bloei had gebracht. ${ }^{\mathrm{I}}$

Hepkema was geen man die graag in de schijnwerpers stond. In de lofredes die bij het graf uitgesproken werden, prees men Hepkema, naast zijn werklust en talent, om zijn eenvoud en nuchterheid. Die eenvoud was zijn hele leven lang zijn handelsmerk geweest. Hij wist zich op te werken in de maatschappij, maar verloor nooit het contact met de lagere klassen. Zijn bladen waren qua inhoud en toon gericht op het volk, Hepkema trok zich het lot van de gewone man aan en hij wist de juiste snaar te raken. Zijn artikelen werden gelezen en Hepkema werd groot in Friesland.

De stijl van zijn blad paste in de ontwikkeling die de Nederlandse pers na de afschaffing van het Dagbladzegel in I869 doormaakte. Er kwamen nieuwe bladen op de markt, die niet alleen goedkoper waren dan de bestaande kranten, maar ook gericht op een breder publiek. Het taalgebruik werd aangepast aan lager opgeleiden en de onderwerpen van de artikelen werden dichter bij huis gezocht. ${ }^{2}$ Hepkema ging zelf de straat op om te horen wat er leefde onder de mensen. En als ergens iets gebeurd was, begaf hij zich naar de plek des onheils. Dat deed hij ook nadat er een gewelddadige inbraak was gepleegd in het plaatsje Britsum, ongeveer tien kilometer ten noorden van Leeuwarden. Hij kon toen nog niet vermoeden dat deze inbraak tot een van de meest omstreden rechtszaken in Nederland zou leiden. ${ }^{3}$ Hepkema's verslagen van de inbraak en de nasleep daarvan bonden vele lezers aan het Nieuw Advertentieblad, zoals zijn blad destijds nog heette. Zijn verhalen waren spannend en meeslepend, met veel aandacht voor sfeer en emotie. 
Hepkema's wijze van verslaggeven stond haaks op de manier waarop de Leeuwarder Courant het deed. Deze krant behield juist veel afstand tot de zaak en beperkte zich uitsluitend tot de feiten zoals die door politie en justitie werden verstrekt. De Leeuwarder Courant stond al sinds 1752 eenzaam aan de top als toonaangevende krant van Friesland. Het was een blad voor de hogere klassen en haar wat deftige stijl sloot aan bij de wensen van dit publiek. Met die formule was de krant altijd succesvol geweest. ${ }^{4}$

In dit artikel wordt bekeken wat de verschillen waren tussen de emotioneel-betrokken stijl van Jacob Hepkema en de beheerst-afstandelijke stijl van de Leeuwarder Courant. ${ }^{5}$ Aan de hand van de artikelen over de Hogerhuiszaak, zoals de nasleep van de inbraak te Britsum genoemd werd, wordt de verslaggeving van beide bladen met elkaar vergeleken. Het doel is om aan te tonen welke stijlelementen Hepkema introduceerde in de Friese pers en om te laten zien waarom het predikaat persvernieuwer voor hem gerechtvaardigd is. ${ }^{6}$

\section{Jacob Hepkema}

Jacob Hepkema werd op 30 mei r 845 geboren in een boerengezin in Oudeschoot, nabij Heerenveen. De familie kende een redelijke welstand en erwas altijd voldoende leesmateriaal aanwezig.? Als kind al las Jacob Hepkema graag, hij hield van Friestalige sprookjes. Toen hij zestien jaar oud was, kwam er een abrupt einde aan het gezinsleven op de boerderij in Oudeschoot. Na een lange periode van gezondheidsproblemen overleed zijn moeder in I86. Dit leidde ertoe dat Jacob en zijn broer Durk bij hun grootouders in het dorpje Dijken gingen wonen. Grootvader Jacob Hepkes Hepkema nam de opvoeding op zich. Hij liet zijn kleinzoons kiezen waarmee zij later de kost wilden verdienen: met de schep of met de pen. Hepkema's broer koos voor de schep, wat betekende dat hij boer werd. De pen bleef dus over voor Jacob, die daarmee was voorbestemd voor een toekomst als leraar.

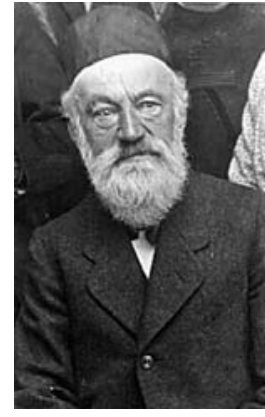

Jacob Hepkema. Bron: www.friesfotoarchief.nl /atlantis

In I867, nadat hij een paar jaar als niet gediplomeerd onderwijzer gewerkt had, besloot Hepkema toelatingsexamen te doen bij de Rijkskweekschool in Haarlem. Hij werd aangenomen en bracht drie jaar door in Haarlem. Het leren ging hem goed af, maar naar zijn zin had hij het er niet. Hij had bijna geen vrije tijd en de opleiding was veel te theoretisch in zijn ogen. De drie jaar vielen hem zwaar. ${ }^{8}$ Uiteindelijk deed hij met goed gevolg eindexamen in I870, keerde terug naar Friesland en werd onderwijzer in Doniaga. Daar had hij plezier in zijn werk en genoot van het plattelandsleven. Ook begon hij zich te interesseren voor maatschappelijke kwesties. Hij schreef de toneelstukken 'Fjouwer rotten yn ien falle' en 'Lean nei wirken' waarin hij opkwam voor de rechten van arbeiders. ${ }^{9} \mathrm{Af}$ en toe bezocht hij politieke bijeenkomsten en het kwam meermalen voor dat hij daar spontane redevoeringen hield, die aandachtig werden beluisterd. 
Ondanks het feit dat Hepkema nu gediplomeerd onderwijzer was, vond hij nog steeds dat hij slecht werd betaald. Zijn broer, die destijds voor de schep gekozen had, verdiende een stuk meer. Hepkema besloot het heft in eigen handen te nemen. Zijn liefde voor het schrijven en het gebrek aan perspectief in zijn toenmalige baan dreven hem naar de journalistiek. In I87 I solliciteerde hij naar een functie bij een uitgeverij in Doetinchem. Hij werd aangenomen en vertrok, met veertig gulden op zak en een koffertje met kleren in de hand. ${ }^{\text {I0 }} \mathrm{Zijn}$ baan in Doetinchem was geen lang leven beschoren. Hepkema had al snel in de gaten dat hij in een slecht bedrijf terechtgekomen was. De directeur gaf te veel geld uit en Hepkema kwam er achter dat het bedrijf in de schulden zat. $\mathrm{Na}$ een paar maanden werd de baas gearresteerd wegens wanbetaling en Hepkema besloot zijn heil elders te zoeken. Hij had zich inmiddels voorgenomen om ooit zelf een krant te beginnen, maar solliciteerde eerst weer naar een functie bij een uitgeverij. Via een omweg kwam hij terecht bij uitgever Hingst in Heerenveen. ${ }^{\text {II }}$

\section{Nieuw Advertentieblad}

In I874, toen hij twee jaar bij Hingst in de zaak werkte, vond Hepkema het tijd om zijn droom van een eigen krant te verwezenlijken. Hij had inmiddels kennis opgedaan van de krantenwereld en ideeën ontwikkeld over hoe zijn eigen blad er uit zou moeten gaan zien. Hij noemde zijn krant het Nieuw Advertentieblad en richtte zich van meet af aan op een breed publiek. De artikelen moesten toegankelijk zijn en naast aandacht voor nieuws uit binnen- en buitenland, kwam ook de eigen regio uitgebreid aan bod. Hepkema wilde de lezer ontspanning bieden na een dag hard werken. De krant moest de lezer op de hoogte houden, maar ook vermaak bieden. Zowel de abonnementskosten als de advertentietarieven probeerde hij laag te houden. ${ }^{\text {I2 }}$

Hepkema's formule sloeg aan. Het aantal abonnees groeide gestaag (zie onderstaande grafiek voor de oplagegroei tussen 1874 en I900). ${ }^{\text {I3 }} \mathrm{Al}$ in november 1874 kwam het wekelijkse Nieuw Advertentieblad uit in een groter formaat. Vijf jaar later werd besloten om een woensdageditie in te voeren. Begin I880 betrok Hepkema, die in 1877 het compagnonschap met Hingst had verbroken, zijn eigen bedrijfspand met drukkerij in Heerenveen. ${ }^{\text {I4 }}$ Hepkema's succes was te danken aan zijn zakelijk inzicht, maar ook aan zijn journalistieke talenten. Zijn maatschappelijke betrokkenheid leidde ertoe dat hij een vertegenwoordiger werd van de journalistieke stijl die bekend is als 'new journalism'. Hij was geïnteresseerd in de werkelijkheid van de straat, van het echte leven. Hoewel hij zijn blad nooit expliciet gebruikte als politiek vehikel, kon men tussen de regels door zijn visie wel herkennen. Waar de journalisten van de Leeuwarder Courant hun nieuws verzamelden bij officiële instanties, deinsde Hepkema er niet voor terug om gewone mensen te vragen naar hun versie van het verhaal. Hij beperkte zijn verslaggeving niet tot de feiten, maar schetste ook de context waarin 
die feiten zich voordeden. Hij verlevendigde zijn verhalen met sfeertekeningen, waardoor het voor zijn doelgroep prettig leesbare stukken werden.

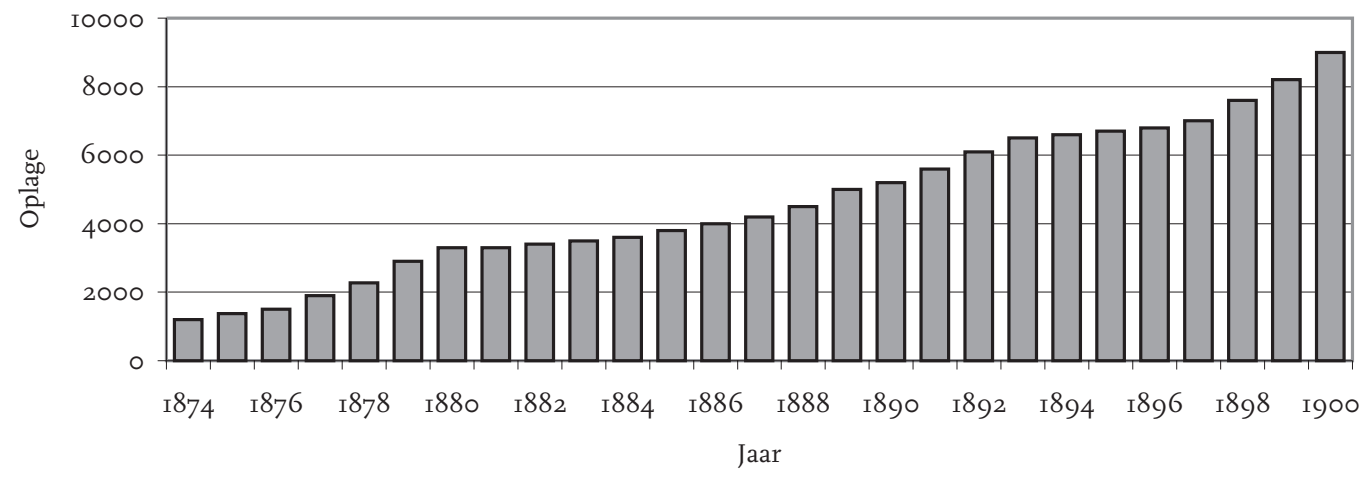

Oplage Nieuw Advertentieblad

\section{Emotioneel-betrokken en beheerst-afstandelijk}

Jacob Hepkema was een van de eerste vertegenwoordigers van de emotioneelbetrokken journalistieke stijl in Friesland. Die stijl leunde sterk op 'new journalism' dat in de Verenigde Staten en Engeland was ontstaan. De ontwikkeling van deze nieuwe stijl was onlosmakelijk verbonden met de commercialisering van de gedrukte nieuwsverslaggeving. De lagere klassen werden beter geschoold, gingen iets beter verdienen en ontwikkelden een sterker maatschappelijk bewustzijn. Zo ontstond er een grote groep nieuwe lezers die behoefte had aan andere bladen dan de gevestigde, meer op de elite gerichte kranten van hun tijd. Er kwamen goedkope bladen, die zich niet alleen wat betreft de kostprijs, maar ook qua vorm en inhoud aanpasten aan het nieuwe lezerspubliek. De journalisten begonnen meer in te spelen op het gevoel van de lezer. Ze gingen op zoek naar spannende onderwerpen en schreven die vervolgens zeer meeslepend en in alledaagse taal op. De koppen werden wervender en het nieuws werd niet langer volgens een vaste ordening geplaatst, maar het meest spectaculaire nieuws kwam voorop de krant. De verslaggever bleef niet achter zijn bureau zitten, maar ging zelf de straat op om de verhalen te zoeken, de sfeer te proeven en zich te mengen onder de mensen. De Engelse new journalists hadden daarnaast idealistische motieven. Zij wilden het belang van het volk dienen door sociale misstanden aan de kaak te stellen en zo de politiek te dwingen tot ingrijpen. ${ }^{\text {I5 }}$

In Nederland begon de opmars van de goedkopere kranten in I869, na de afschaffing van het Dagbladzegel. Het Dagbladzegel was een belasting op het maken van kranten, die de vervaardiging daarvan tamelijk kostbaar maakte. De overheid slaagde er zo jarenlang in de pers te beteugelen, maar het politieke draagvlak voor de maatregel kalfde af en de Nederlandse journalistiek werd van 
dit juk verlost. Vanaf toen werd new journalism door progressieve journalisten geleidelijk overgenomen, maar het ging langzaam en niet alle elementen werden gekopieerd. De actieve journalistieke houding viel wel in goede aarde en steeds meer Nederlandse verslaggevers gingen rond de eeuwwisseling voor kortere of langere tijd op pad om verhalen te verzamelen. Ze mengden zich onder de mensen op straat, toonden belangstelling voor de dingen die daar gebeurden en lieten de voorbijgangers ook aan het woord in hun artikelen. De journalisten kwamen hierdoor dichter bij hun lezerspubliek te staan. Het Nieuws van den Dag (I870), De Echo (I88I) en De Telegraaf (I893) waren enkele belangrijke kranten die in Nederland groot werden met moderne journalistiek. ${ }^{16}$

Nieuwe genres als interviews en reportages werden geïntroduceerd in de krant. De artikelen werden aantrekkelijk gemaakt met welhaast literaire sfeertekeningen, waardoor de lezer het gevoel kreeg zelf bij de gebeurtenis aanwezig te zijn. Er was veel oog voor detail en ook werden er betekenissen toegekend aan de verschijningsvormen en uiterlijkheden van de zaken of mensen die beschreven werden. Deze naturalistische inslag werd gebruikt om de werkelijkheid zo duidelijk en begrijpelijk mogelijk over te brengen op de lezer. Zo ontwikkelde zich een Nederlandse versie van new journalism, de emotioneel-betrokken stijl. ${ }^{\text {T7}}$

De emotioneel-betrokken stijl was het alternatief voor de beheerst-afstandelijke journalistieke stijl die van oudsher in Nederland bestond. Kranten waren eeuwenlang luxeartikelen die alleen weggelegd waren voor de rijkere en ontwikkelde klasse. Vanzelfsprekend hadden de kranten zich dus in alle opzichten gevormd naar de wensen van die lezersgroep. Een krant moest ervoor zorgen dat de lezers op de hoogte bleven van politieke en economische ontwikkelingen en moest tevens de geest scherp houden met artikelen over kunst en wetenschap. Het nieuws werd gehaald bij de officiële instanties zelf, van kritische verslaggeving zoals wij die nu kennen was nog geen sprake. Het weergeven van de feiten werd beschouwd als objectiviteit en dat was een belangrijke waarde. De artikelen werden opgeschreven in de taal van de elite en dat betekende lange zinnen met veel dure woorden. Het nieuws werd in een vaste orde aangeboden, waarbij de feiten zakelijk en met distantie werden gebracht. De krant leverde de lezer de informatie aan die hij nodig had voor het vormen van zijn opinie, zodat hij kon deelnemen aan het publieke debat over de stand van zaken in de wereld. ${ }^{\text {I8 }}$

\section{Voorbeelden uit de verslaggeving van Hepkema en de Leeuwarder Courant}

Hepkema had een sterk ontwikkeld rechtvaardigheidsgevoel en verfoeide de klassenjustitie, die in zijn tijd veelvuldig voorkwam. Zijn grootvader had ooit eens moeten getuigen in een rechtszaak tegen een heer van stand, die hij bekeurd had wegens illegaal jagen op het landgoed van de familie Van Eysinga. De man had voor de rechtszaak twee arbeiders omgekocht om hem van een alibi te voorzien. Hepkema senior hield echter voet bij stuk en toen het bedrog uit- 
kwam, gingen de arbeiders voor vijf jaar de gevangenis in, terwijl de hoge heer zelf vrijgesproken werd. ${ }^{\text {I9 }}$ Dit verhaal is Hepkema altijd bijgebleven en wellicht speelde het een rol in de manier waarop hij verslag deed van het dubieuze proces tegen drie arbeiders in 1896.

Op 5 december 1895 pleegden drie gemaskerde mannen een inbraak in Britsum. Toen twee van hen de boerderij binnendrongen, raakten zij in gevecht met de bewoner Gatze Haitsma en een logé, Sieds Jansma. Over en weer werden schoten gelost en Jansma raakte ernstig gewond. De inbrekers sloegen zonder buit op de vlucht en wisten te ontkomen. Het was een spectaculair verhaal en Jacob Hepkema meldde zich een aantal dagen later op de boerderij om met de bewoners te praten over hetgeen hen was overkomen. Naar aanleiding van dit gesprek schreef hij een lang en spannend artikel over de bewuste avond. Het zou het eerste artikel zijn in een lange reeks over deze zaak, die later bekend zou worden als de Hogerhuiszaak, een van de meest omstreden rechtszaken op Nederlandse bodem. ${ }^{20}$

Een paar weken na de inbraak werden de drie broers Wybren, Keimpe en Marten Hogerhuis uit Beetgumermolen gearresteerd. Hoewel het bewijs tegen de drie zeer mager was, werden ze veroordeeld tot lange gevangenisstraffen. Het vonnis van de gebroeders Hogerhuis leidde tot felle protesten van de arbeidersbeweging in heel Nederland. S DAp-kamerlid Pieter Jelles Troelstra spande zich in voor hun vrijlating en sneed het onderwerp meermalen aan in de Tweede Kamer. Het mocht allemaal niet baten, de gebroeders Hogerhuis bleven vastzitten. Hepkema volgde de zaak van begin tot eind en publiceerde uitgebreide verslagen van alle facetten. Hij deed zelf onderzoek en kwam tot de conclusie dat de gebroeders Hogerhuis onschuldig moesten zijn.

Aandacht voor het wel en wee van de gewone man was een belangrijk kenmerk van de emotioneel-betrokken stijl. Hepkema toonde deze aandacht gedurende het hele verloop van de Hogerhuiszaak, vooral door zelf met de betrokkenen te spreken en poolshoogte te nemen in de omgeving waar de gebeurtenissen zich hadden afgespeeld. Na de inbraak ging hij zelf naar de plek van de misdaad toe en sprak langdurig met de bewoners. De sporen van de vechtpartij waren nog zichtbaar. 'Hoitsma is nog al bekrabt op zijn gelaat (...)', observeerde Hepkema. Hij schetste de omgeving, die hij zelf gezien had. 'Op den zoogenaamde Driesprong, waar de Schriedijk, de Hooge Dijk en een derde kunstweg, die naar Stiens voert, te zamen komen, staan vrij eenzaam een kleine en een groote boerderij aan weerskanten van den Schriedijk. ${ }^{21}$ Korte tijd later bezocht hij Sieds Jansma, die tijdens de inbraak neergeschoten was, in het ziekenhuis. Die werd zelfs letterlijk geciteerd en geparafraseerd in het artikel. 'Sies Jansma, de moedige schipper, die nog altijd ernstig gewond het bed moet houden, met een kogel in de bovendij, die niet verwijderd zal kunnen worden, verklaarde, wel ietwat paradoxaal: was ik er niet geweest, dan was 't waarschijnlijk beter afgeloopen, beter voor ons en beter voor de inbrekers. ${ }^{22}$ Toen de gebroeders Hogerhuis gearresteerd werden, beschreef Hepkema hoe hij zag dat ze afgevoerd wer- 
den door de marechaussee. Hij ging naar Beetgum en verzamelde zoveel mogelijk informatie over hen. Hij wist hun beroepen, hun woonsituatie en hobby's en schreef dat het hele gewone mannen waren, zonder crimineel verleden. 'Zoo niet van alle, dan toch van vele zijden hoort men van den verver [Wybren] met lof gewagen; niemand kan haast gelooven aan zijne schuld'. Overigens noemde Hepkema ze met naam en toenaam en meldde hij zelfs in welke straat ze woonden. Privacy was een nog onbekend fenomeen. ${ }^{23}$

De aandacht van de Leeuwarder Courant voor de zaak was nihil. Er verschenen in totaal drie berichtjes in telegramstijl, waarin kort melding werd gemaakt van de inbraak. De zaak had geen belang voor de Leeuwarder Courant. Die begaf zich niet ter plaatse, maar dat had de krant naar alle waarschijnlijkheid ook niet gedaan als het wel een zaak van belang was geweest. ${ }^{24}$ De informatie in de korte artikeltjes werd vermoedelijk door de politie aangeleverd. Het hele verslag van de inbraak luidde als volgt: 'Drie vermomde kerels drongen binnen. Toen de jonge S.J. onraad vernam, sprong hij het bed uit, op hen af en greep een van hen. De twee anderen wilden hun makker bevrijden en schoten S.J. in de beenen. ${ }^{25}$ In het laatste van de drie artikeltjes, waarin gemeld werd dat de 'drie gebroeders H.' gearresteerd waren, zwaaide de Leeuwarder Courant de politie lof toe: 'Naar men verneemt, heeft de Leeuwarder politie tot dezen uitslag niet weinig medegewerkt'. ${ }^{26}$ De goede band die de krant met de autoriteiten had, werd hierdoor onderstreept.

Hepkema's verslaggeving was duidelijk meer sensatiebelust. Hij speelde goed in op het gevoel van zijn lezers. Hij wist actie en emotie in zijn verhalen te stoppen. Het verslag van de inbraak zelf was spectaculair en las als een korte roman. 'Haitsma sprong gezwind van 't bed en viel op hem aan, roepende: "hwet is mij dat hjir!” - “'t Is mij voor den bliksem te doen om je geld!” was 't wederwoord met verdraaide stem op zijn hoog-Hollandsch. ${ }^{27}$ Hepkema zorgde voor sfeertekeningen die de lezer het gevoel gaven zelf bij de gebeurtenis aanwezig te zijn. 'Slechts een flauw maanlicht wierp nu nog een mat schijnsel in de spookachtige ruimte waar wanhopig gestreden werd op leven en dood'. ${ }^{28}$ Ook in de rechtbankverslagen die volgden op de artikelen over de inbraak, wist Hepkema emotie te stoppen. In het slot van een verslag van een lange zitting, plaatste hij de volgende observatie: 'Onder het heengaan roept de moeder der drie jonge mannen haren zoons met bewogen stem toe: "Mar goed hâlde, hear!”, ${ }^{29}$ Hepkema zag zijn geloof in de onschuld van de broers bevestigd in hun uiterlijk. 'Een ongunstig uiterlijk heeft geen van de drie. Wel ligt er iets in hun voorkomen, dat spreekt van ondernemen en durven. ${ }^{30}$ Dit toeschrijven van betekenissen aan uiterlijke verschijningsvormen is een voorbeeld van de naturalistische inslag die de moderne journalistiek had. ${ }^{3 \mathrm{I}}$

De Hogerhuiszaak kreeg pas meer aandacht van de Leeuwarder Courant toen zij een institutioneel karakter gekregen had in de rechtszaal. De zaak was nu in het domein van de autoriteiten gekomen. De krant behandelde de zaak met veel meer distantie dan Hepkema. De ruimte die aan de verschillende getuigenissen 
besteed werd, was evenredig aan de tijd die zij in de rechtszaal in beslag hadden genomen. In de verslagen van de rechtszittingen nam de Leeuwarder Courant de teksten het liefst zo letterlijk mogelijk over. Het was alsof de krant een griffier naar de rechtbank had gestuurd, in plaats van een verslaggever:

'Zooals we reeds met een enkel woord meedeelden, hebben gisteren voor de Rechtbank alhier, kamer van strafzaken, gepresideerd door den heer mr. C. W. de Vriese, terecht gestaan Wiebren Hogerhuis, 32 jaren; Marten Hogerhuis, 26 jaren, en Keimpe Hogerhuis, 36 jaren, arbeiders te Beetgum, thans in hechtenis, ter zake dat zij in den nacht van 5 op 6 December 1895 te zamen en in vereeniging met elkander, het oogmerk hebbende om zich het geld en de geldswaarden of goederen van den gaardenier G. Haitsma onder Britsum toe te eigenen (...). ${ }^{32}$

Datzelfde gold voor de behandeling van de Hogerhuiszaak in de Tweede Kamer. Beide kranten besteedden hier veel aandacht aan, op basis van door derden aangeleverde artikelen. Het verslag van de Leeuwarder Courant was zo gedetailleerd dat het overkomt als een soort parafraserende samenvatting. Geciteerd werd er niet, maar de lezer krijgt het gevoel dat hij het debat bijna woordelijk kan volgen:

'De heer Troelstra herneemt, dat die houding groote ontsteltenis heeft gewekt: zij gaf aan de zaak het hatelijke en het "empörende" van de zaak Dreyfus en Het Vaderland en prof. Treub in het Sociaal Weekblad spraken het woord partijdigheid uit. Moet 't niet het rechtsgevoel krenken des volks, wanneer personen die voor de waarheid willen opkomen, tot 8 maanden gevangenisstraf worden veroordeeld? ${ }^{33}$

De Leeuwarder Courant besteedde echter aan elk Kamerdebat een hoop aandacht, terwijl Hepkema juist het gedeelte over de Hogerhuiszaak er uit lichtte en de rest van het debat, dat eigenlijk ging over de begroting van Justitie, wegliet. Hepkema liet het verslag een paar dagen later volgen door wat verzamelde citaten uit andere kranten over het debat. Deze werden aangeboden ter vermaak van de lezer, maar er bleek ook een sterke partijdigheid uit. Uit het Volksdagblad werd de volgende sneer overgenomen: 'Midden in den strijd kwam de heer Staalman als een slijmerige slak naar de beide strijders [Troelstra en Cort van der Linden] toegekropen ten einde Troelstra te doen uitglijden. Troelstra gleed niet uit'..$^{34}$

De Leeuwarder Courant had de pretentie dit soort waardeoordelen niet te vellen, maar liet tussen de regels door wel eens een denigrerende toon horen. In augustus I 898 werd in Leeuwarden een protestmeeting gehouden voor de vrijlating van de gebroeders Hogerhuis. In het verslag van deze socialistische bijeenkomst kon de krant de volgende opmerkingen niet laten. Er werd een motie 
aangenomen om de socialisten niet 'hatelijk tegenover elkaar te laten staan, zooals, gelijk men weet, vroeger is voorgekomen'. Als slotzin meldde de Leeuwarder Courant over de twee bijeenkomsten van die dag: 'Beide liepen in goede orde af. ${ }^{35}$ Hepkema was juist ter plaatse en leverde een gedetailleerd verslag van de meeting. Niet alleen de betogen werden uitgebreid weergegeven, ook het human interest gehalte was weer hoog. Zo schreef Hepkema over een klein kind dat begon te huilen tijdens de woorden van de eerste spreker.

'Och, zou u zo goed willen zijn, $u$ in 't belang der goede orde met dat kind te verwijderen, vroeg de Voorzitter de vrouw. Ja, antwoordde de kleine op schreienden toon. Hierop volgde een uitbundig gelach. ${ }^{36}$

\section{Tot slot}

Jacob Hepkema was niet afkomstig uit de arbeidersklasse, maar kwam ook zeker niet uit elitaire kringen. Hij was opgegroeid in comfortabele eenvoud en een daarbij passende loopbaan als leraar leek voor hem weggelegd. Hij wilde zich echter niet neerleggen bij deze voorspelbare toekomst. Hepkema verzette zich tegen de door de maatschappij vastgelegde paden voor sociale klassen. De journalistiek, als opkomende bedrijfstak, bood hem de mogelijkheid tot sociale stijging. Hepkema verloor daardoor echter niet zijn maatschappelijke visie. Hij kwam voort uit het volk, sprak de taal daarvan en voelde zich verbonden met het lot van de gewone man. Die betrokkenheid vertaalde zich in redactionele keuzes, zoals de onderwerpskeuze, zijn actieve manier van nieuwsgaring en de toegankelijke schrijfstijl.

De Hogerhuiszaak was een zaak waarin de tegenstellingen tussen arm en rijk in de samenleving op scherp gezet werden. Hoewel Hepkema nooit expliciet partij koos, liet de manier waarop hij de zaak aanpakte duidelijk zien waar zijn sympathie lag. En passant deed hij dingen, die nieuw waren in de journalistiek. Hij ging naar de plek waar de inbraak gepleegd was, sprak met de slachtoffers en stelde zelfs een eigen onderzoek in naar de daders. Mede op basis daarvan concludeerde hij dat de verdachten die uiteindelijk aangehouden werden, niet schuldig konden zijn. De onzorgvuldigheid van de politie en de beschuldigingen van klassenjustitie maakten de zaak tot een sociale kwestie. Hepkema nam het in zijn artikelen op voor de verdachte gebroeders Hogerhuis. Later steunde hij de acties om hen vrij te krijgen met publiciteit in zijn blad. Hepkema's meeslepende artikelen over de zaak werden zeer populair. De nieuwe journalistieke stijl die hij toepaste, sloeg aan bij het nieuwe lezerspubliek. ${ }^{37}$

Hepkema was in Friesland veruit de succesvolste exponent van deze nieuwe stroming in de pers en hij vergaarde zoveel abonnees dat hij een geduchte concurrent werd voor de Leeuwarder Courant die toen al meer dan een eeuw de dienst uitmaakte in Friesland. Het Nieuw Advertentieblad zou uiteindelijk over- 
gaan in twee andere kranten, het Nieuwsblad van Friesland en het Leeuwarder Nieuwsblad, die vlak voor de Tweede Wereldoorlog gezamenlijk een grotere oplage hadden dan de Leeuwarder Courant..$^{8}$ Op dat moment had de Leeuwarder Courant zich uiteraard al flink aangepast aan de nieuwe journalistieke wind die in Friesland waaide. Onder invloed van de concurrentie van Hepkema, werd de Leeuwarder Courant goedkoper en ook inhoudelijk bleef de krant niet stilstaan. De stijlelementen die Hepkema zo populair maakten, werden geleidelijk overgenomen. $^{39}$

Hepkema vernieuwde niet alleen door middel van zijn eigen blad, hij dwong daarmee zelfs de marktleider in Friesland tot modernisering. Kortom, Jacob Tjebbes Hepkema zorgde eigenhandig voor de modernisering van de Friese pers aan het einde van de negentiende eeuw en zette daarmee de toon voor de wijze waarop de journalistiek in Friesland zich tot ver in de twintigste eeuw zou blijven ontwikkelen.

I Nieuwsblad van Friesland, I5 juli I9I9; Leeuwarder Nieuwsblad, I8 juli I9I9; Leeuwarder Courant, I4 juli I9I9, I8 juli I9I9.

2 H. Wijfjes, Journalistiek in Nederland 1850-2000. Beroep, cultuur en organisatie, Amsterdam 2004, p. 33-72.

3 J. Frieswijk \& H. Sleurink, De zaak Hogerhuis. Eene gerechtelijke misdaad, Leeuwarden I984; U.D. Hannema, De Hogerhuis-zaak, Drachten I964.

4 M. Broersma, Beschaafde vooruitgang. De wereld van de Leeuwarder Courant 1752-2002, Leeuwarden 2002.

5 Het onderscheid tussen deze stijlen is ontleend aan: M. Broersma, 'Botsende stijlen. De Eerste Wereldoorlog en de Nederlandse journalistieke cultuur', Tijdschrift voor mediageschiedenis, I999, nr.2, p. 40-68.

6 Dit artikel is gebaseerd op mijn afstudeerscriptie: 'Jacob Tjebbes Hepkema. Persvernieuwer in Friesland' (RU) Groningen 2004.

7 J. Hepkema, Fen ús eigen stamme Hepkema (I89I), Hepkema Archief (Tresoar, Leeuwarden), inventarisnummer 762 4; J.J. Hof, 'J. Hepkema yn libben en wirk', Swanneblommen 2, I920, p. I8-19.

8 Hof, 'J. Hepkema', p. 20.

9 'Vier ratten in één val'. 'Loon naar werken'.

Io Hof, 'J. Hepkema', p. 82.

II Ibidem, p. 85-87.

I2 Proefnummer Nieuw Advertentieblad, Heerenveen I873.

I3 Bron: Hepkema Archief, inventarisnummer 32I.

I4 Proefnummer Nieuw Advertentieblad, 3I december I879; Nieuwsblad van Friesland, Extra bijblad, 5 december 1930 .

I5 Wijfjes, Journalistiek in Nederland, p. 29-33.

I6 Ibidem, p. 38-40.

I7 Ibidem, p. 33-72; Broersma, 'Botsende stijlen', p. 40-68.

I8 Broersma, Beschaafde vooruitgang, p. 254-255 en p. 267-272.

I9 Hepkema, Fen ús eigen stamme, p. 9.

20 Frieswijk \& Sleurink, De zaak Hogerhuis; Hannema, De Hogerhuis-zaak.

2I Nieuw Advertentieblad, II december I895. 
22 Ibidem, I8 december 1895.

23 Ibidem, 4 januari 1896.

24 Broersma, Beschaafde vooruitgang, p. 258.

25 Leeuwarder Courant, 7 december 1895.

26 Ibidem, I januari 1896.

27 Nieuw Advertentieblad, II december I895.

28 Ibidem.

29 Ibidem, 6 juni ı896. ('Houd je taai!')

30 Ibidem.

3 I Wijfjes, Journalistiek in Nederland, p. 62-65.

32 Leeuwarder Courant, 5 juni I896.

33 Ibidem, 9 december 1898 .

34 Nieuw Advertentieblad, I4 december I898.

35 Leeuwarder Courant, 2 augustus I898.

36 Nieuw Advertentieblad, 3 augustus I898.

37 Alle acties hebben tenslotte nog wel iets uitgehaald voor de in I 896 tot langdurige gevangenisstraffen veroordeelde broers. Uiteindelijk werden zij in respectievelijk I9०I, I902 en I90 5 in vrijheid gesteld, maar rechtsherstel werd ze niet verleend.

38 Broersma, Beschaafde vooruitgang, p. 250.

39 Ibidem, p. 272-277. 